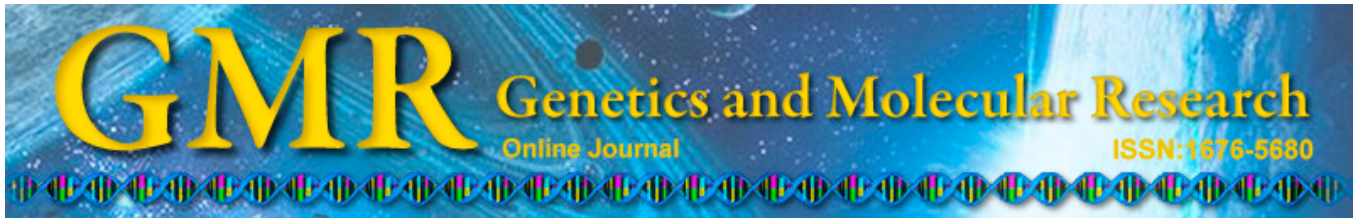

\title{
Use of microsatellite markers to assign goats to their breeds
}

\author{
R.S. Aljumaah, M.M. Alobre and R.M. Al-Atiyat \\ Animal Production Department, College of Food and Agriculture Sciences, \\ King Saud University, Kingdom of Saudi Arabia \\ Corresponding author: R.M. Al-Atiyat \\ E-mail: ralatiyat@ksu.edu.sa / raedatiyat@yahoo.com
}

Genet. Mol. Res. 14 (3): 9071-9080 (2015)

Received October 28, 2014

Accepted May 8, 2015

Published August 7, 2015

DOI http://dx.doi.org/10.4238/2015.August.7.16

\begin{abstract}
We investigated the potential of 17 microsatellite markers for assigning Saudi goat individuals to their breeds. Three local breeds, Bishi, Jabali, and Tohami were genotyped using these markers, and Somali goats were used as a reference breed. The majority of alleles were shared between the breeds, except for some that were specific to each breed. The Garza-Williamson index was lowest in the Bishi breed, indicating that a recent bottleneck event occurred. The overall results assigned the goat individuals (based on their genotypes) to the same breeds from which they were sampled, except in a few cases. The individuals' genotypes were sufficient to provide a clear distinction between the Somali goat breed and the others. In three factorial dimensions, the results of a correspondence analysis indicated that the total variation for the first and second factors was 48.85 and $31.43 \%$, respectively. Consequently, Jabali, Bishi, and Tohami goats were in separate groups. The Jabali goat was closely related to the Bishi goat. Somali goats were distinguished from each other and from individuals of the other three goat breeds. The markers were successful in assigning individual goats to their breeds, based on the likelihood of a given individual's genotype.
\end{abstract}

Key words: Goat; Microsatellite; Individual assignment test; Conservation 


\section{INTRODUCTION}

The ubiquity of the domestic goat is due to its high adaptive capacity and performance in different environmental conditions and production systems (Galal, 2005). Their adaptability in these different conditions is assumed to be as a result of natural selection (Peters and Horst, 1981). Consequently, the goat's genetic resources have been exchanged between breeds worldwide (Rodero et al., 1992). They also exhibit great morphological variety in horn shape, ear shape, body conformation, and hair color. This great phenotypic diversity is mainly due to the goat's ability to adapt to various environmental conditions (FAO, 2007).

The world goat population is estimated to be over 921 million individuals of 570 breeds (FAOSTAT, 2013). The goat population in the Kingdom of Saudi Arabia (KSA) includes several breeds, namely Ardi, Hejazi, Bishi, Jabali, and Tohami (Al-Khouri, 1996; AlAmer, 2003; FAO, 2004; Canon et al., 2006). The latter three breeds are reared in the southern part of KSA, but it is often difficult to visually distinguish them. Therefore, assigning individuals to a predefined breed is a population genetics assignment test, which can be resolved by identifying migrants and mixed-breed individuals. The individual assignment test is based on estimating population alleles in circumstances where many individuals are either migrants or of mixed-breed (Pritchard et al., 2000), and utilizes individual genotypes to assign individuals to populations or clusters (Paetkau et al., 1995). Given a set of allele frequencies of the population studied, it is possible to estimate a given individual's genotype. The application of assignment tests includes identifying individuals that have been exchanged between populations (Cegelskiet al., 2003), identifying immigrants (Castric and Bernatchez, 2004), detecting hidden population structures (Peter et al., 2006), parentage analysis, and tracing animals and animal products to their breeds of origin (Shackell et al., 2001). Microsatellite markers are the most common DNA markers used in successful individual assignment tests (Evett and Wier, 1998; Sunnucks, 2001; Selkoe and Toonen, 2006). In this study, a panel of microsatellite markers was used for assigning Saudi goats to their breeds.

\section{MATERIAL AND METHODS}

\section{Blood sampling}

A total of 34, 44, and 17 individuals (95 in total) of Jabali, Bishi, and Tohami goats, respectively, from the Jazan Province of southern KSA were blood sampled (Figure 1). Blood samples from mature unrelated males and females of each breed were randomly collected from seven different herds in five areas. In addition, 12 individuals of a Somali goat breed were also blood sampled as a reference. The collected blood samples were transferred to an icebox and refrigerated until DNA extraction was performed.

\section{DNA extraction and genotyping}

DNA extraction was performed using a commercially available genomic DNA extraction kit (Amersham Biosciences). The DNA was quantified and purified using a NanoDrop ${ }^{\circledR}$ DNA spectrophotometer. Polymerase Chain Reaction (PCR) amplification was performed using a GeneAmp ${ }^{\circledR}$ PCR system 9700. The PCR mixture was prepared according to recommended protocols (Sambrook et al., 1989). Seventeen markers were used for DNA genotyp- 
ing, following the recommendations of the International Society for Animal Genetics (FAO, 2007) (Table 1). The resulting raw data, that represented the allele sizes for each marker, were immediately visualized, scored, and then saved into a specific file format using GeneMapper ${ }^{\mathbb{B}}$ software (Applied Biosystems).

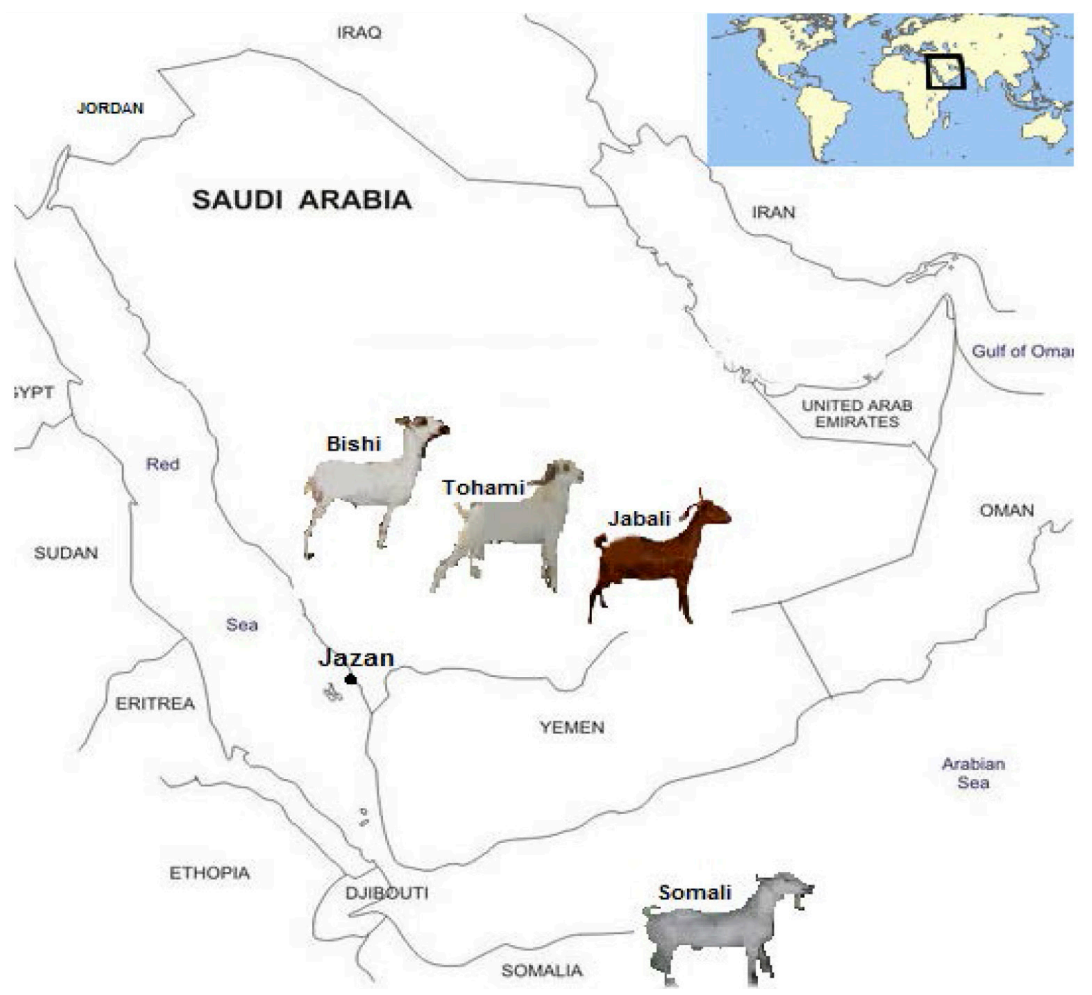

Figure 1. Locations of the four goat breeds studied.

Table 1. Microsatellite markers, chromosome numbers, locations, regions, expected allele sizes and species origins.

\begin{tabular}{rlccccc}
\hline No. & Marker & Chr. No. & Location $(\mathrm{cM})$ & Region & Size (bp) & Origin \\
\hline 1 & INRA63 & 18 & 26 & CH1 & $168-210$ & Bovine \\
2 & ILSTS029 & 3 & 20 & BTA & $135-185$ & Bovine \\
3 & OarFCB48 & 17 & 35 & OAR & $149-173$ & Ovine \\
4 & OARFCB20 & 2 & 190.2 & OAR & $93-112$ & Ovine \\
5 & SRCRSP3 & 10 & 36 & CH1 & $95-135$ & Caprine \\
6 & MAF209 & 17 & 21.9 & CH1 & $100-104$ & Bovine \\
7 & MAF70 & 4 & 13 & BTA & $120-190$ & Bovine \\
8 & OarAE54 & 25 & 63.2 & OAR & $105-145$ & Ovine \\
9 & ETH10 & 5 & 51.3 & CH1 & $190-220$ & Bovine \\
10 & ILSTSO11 & 14 & 120.3 & BTA & $250-300$ & Bovine \\
11 & MCM527 & 5 & 29.8 & OAR & $155-195$ & Ovine \\
12 & MAF65 & 15 & 29.5 & BTA & $134-132$ & Ovine \\
13 & SPS113 & 10 & 10 & BTA & $234-256$ & Bovine \\
14 & INRABERN172 & 26 & BTA & $195-229$ & Bovine \\
15 & DRBP1 & 23 & 34.11 & ORA & $220-247$ \\
16 & CSRD247 & 14 & BTA & $118-200$ \\
17 & BM6444 & 2 & & & Bvine \\
\hline
\end{tabular}




\section{Genetic data analysis}

The average number of alleles per locus (A) and the allele frequency were estimated using the CERVUS software package, version 2.0 (Marshallet al., 1998). The individual assignment test was computed using ARLEQUIN (version 3.11) (Excoffier et al., 2005). The Garza-Williamson $(G-W)$ index was used for identifying population bottlenecks (Garza and Williamson, 2001), and the GENETIX (version 4.05) software was used to assign the individuals to their breeds (Belkhir et al., 1996-2002).

\section{RESULTS}

\section{Genetic variation within populations}

\section{Allele size and frequency}

The alleles found at the 17 loci and their frequencies in each goat breed are presented in Figure 2. There was a large number of marker alleles and wide range of allele sizes for each locus, except for MAF209 and ETH10, which had three and four alleles, respectively. There was no similar pattern of allele frequencies profile at each locus. Six loci (OarAE54, SPS113, $M A F 70$, INRABERN172, MAF209, and DRBP1) had normal allele frequency and size distributions (Figure 2). Such profiles are similar to a normal distribution, and thus could be used to predict the evolutionary forces responsible. Despite the other frequency profiles having no specific pattern, some obvious similarities were noticed, such as between BM6444, SRCRSP3, OarFCB 48, MAD65, OarFCB20, and ILSTS029. Extremely high allele frequencies were observed at the locus and population levels (Figure 2). For example, allele 102 at MAF209 was the most frequent allele in the four breeds, followed by allele 190 at BM6444 in the three Saudi breeds (Figure 2). However, it was noticed that the most frequent allele in one breed was frequently found in the others, with some exceptions, such as allele 132 at MAF65 in the Tohami breed. In some cases, however, it was vice versa (Figure 2).

In general, the majority of the alleles were found in all three Saudi breeds, except for alleles with either low frequencies or extreme sizes. These alleles were considered private or breed-specific, and were not shared between the breeds. Table 2 lists the 51 private alleles with their corresponding allele frequencies and sizes. The largest number of private alleles was found in Somali goats (19), 17 were found in Jabali goats, 8 were found in Tohami goats, and 7 were found in Bishi goats. In general, the private alleles were of extreme size in all of the breeds, and loci usually occurred at very low frequencies. With a few exceptions, the most frequently observed private alleles were at low frequencies within breeds. These cases were all in either Somali or Tohami goats, and ranged from $10 \%$ for allele 242 at locus OarFCB 48 in the Tohami breed to $33 \%$ for allele 139 at locus SPS113 in Somali goats (Table 2).

The $G-W$ index in the Jabali breed was low for three loci (BM6444, SRCRSP3, and CSRD247), with values lower than 0.1 (Figure 3). Therefore, there was little variation in allele size at these three loci, whereas the rest of the loci had high genetic variation. The $G-W$ statistic is very small in populations that have been through a bottleneck, and close to 1 in stable populations. The lowest $G-W$ value in the Bishi breed was at the loci BM6444 and SRCRSP3; therefore, there was low allele size variation at these loci. The rest of the loci had diverse allele sizes, which ranged from 25 to $65 \%$. In the Tohami and Bishi breeds, a similar result was 
obtained at these loci, indicating that they had low allele size variation. However, a few loci had $G-W$ values that ranged from 30 to $70 \%$ (Figure 3).

Table 2. Private allele sizes (bp) and corresponding allele frequencies.

\begin{tabular}{|c|c|c|c|c|c|c|c|c|c|}
\hline No. & Locus & Allele & Frequency & Population & No. & Locus & Allele & Frequency & Population \\
\hline 1 & OarAE54 & 121 & 0.063 & Tohami & 27 & OarFCB 48 & 165 & 0.050 & Tohami \\
\hline 2 & OarAE54 & 117 & 0.014 & Jabali & 28 & OarFCB 48 & 242 & 0.100 & Tohami \\
\hline 3 & OarAE54 & 135 & 0.027 & Jabali & 29 & OarFCB 48 & 145 & 0.048 & Bishi \\
\hline 4 & OarAE54 & 147 & 0.027 & Jabali & 30 & OarFCB 48 & 163 & 0.054 & Jabali \\
\hline 5 & SPS113 & 139 & 0.333 & Somali & 31 & CSRD247 & 242 & 0.056 & Somali \\
\hline 6 & SPS113 & 149 & 0.013 & Jabali & 32 & CSRD247 & 248 & 0.167 & Somali \\
\hline 7 & ILSTOII & 268 & 0.026 & Jabali & 33 & CSRD247 & 210 & 0.250 & Tohami \\
\hline 8 & $M A F 70$ & 140 & 0.167 & Somali & 34 & CSRD247 & 208 & 0.188 & Tohami \\
\hline 9 & $M A F 70$ & 160 & 0.083 & Somali & 35 & CSRD247 & 204 & 0.188 & Tohami \\
\hline 10 & MAF70 & 164 & 0.083 & Somali & 36 & CSRD247 & 228 & 0.024 & Bishi \\
\hline 11 & $M A F 70$ & 158 & 0.040 & Bishi & 37 & CSRD247 & 176 & 0.032 & Jabali \\
\hline 12 & $M A F 70$ & 166 & 0.019 & Jabali & 38 & MAF65 & 116 & 0.031 & Bishi \\
\hline 13 & MCM527 & 153 & 0.013 & Jabali & 39 & $D R B P 1$ & 153 & 0.063 & Somali \\
\hline 14 & BM6444 & 160 & 0.083 & Somali & 40 & $D R B P I$ & 107 & 0.023 & Bishi \\
\hline 15 & BM6444 & 164 & 0.083 & Somali & 41 & $D R B P I$ & 139 & 0.045 & Jabali \\
\hline 16 & BM6444 & 162 & 0.083 & Somali & 42 & $D R B P I$ & 115 & 0.045 & Jabali \\
\hline 17 & BM6444 & 136 & 0.038 & Tohami & 43 & OarFCB20 & 107 & 0.063 & Somali \\
\hline 18 & BM6444 & 124 & 0.026 & Bishi & 44 & OarFCB20 & 103 & 0.188 & Somali \\
\hline 19 & BM6444 & 148 & 0.026 & Bishi & 45 & OarFCB20 & 109 & 0.012 & Jabali \\
\hline 20 & BM6444 & 168 & 0.022 & Jabali & 46 & OarFCB20 & 85 & 0.048 & Jabali \\
\hline 21 & BM6444 & 166 & 0.043 & Jabali & 47 & ILSTSO29 & 129 & 0.125 & Somali \\
\hline 22 & SRCRSP3 & 173 & 0.056 & Tohami & 48 & ILSTSO29 & 121 & 0.125 & Somali \\
\hline 23 & SRCRSP3 & 123 & 0.012 & Jabali & 49 & ILSTSO29 & 133 & 0.125 & Somali \\
\hline 24 & SRCRSP3 & 111 & 0.049 & Jabali & 50 & ILSTSO29 & 123 & 0.250 & Somali \\
\hline 25 & INRABERN172 & 256 & 0.111 & Somali & 51 & ILSTSO29 & 119 & 0.250 & Somali \\
\hline 26 & INRABERNIT2 & 250 & 0.056 & Somali & & & & & \\
\hline
\end{tabular}

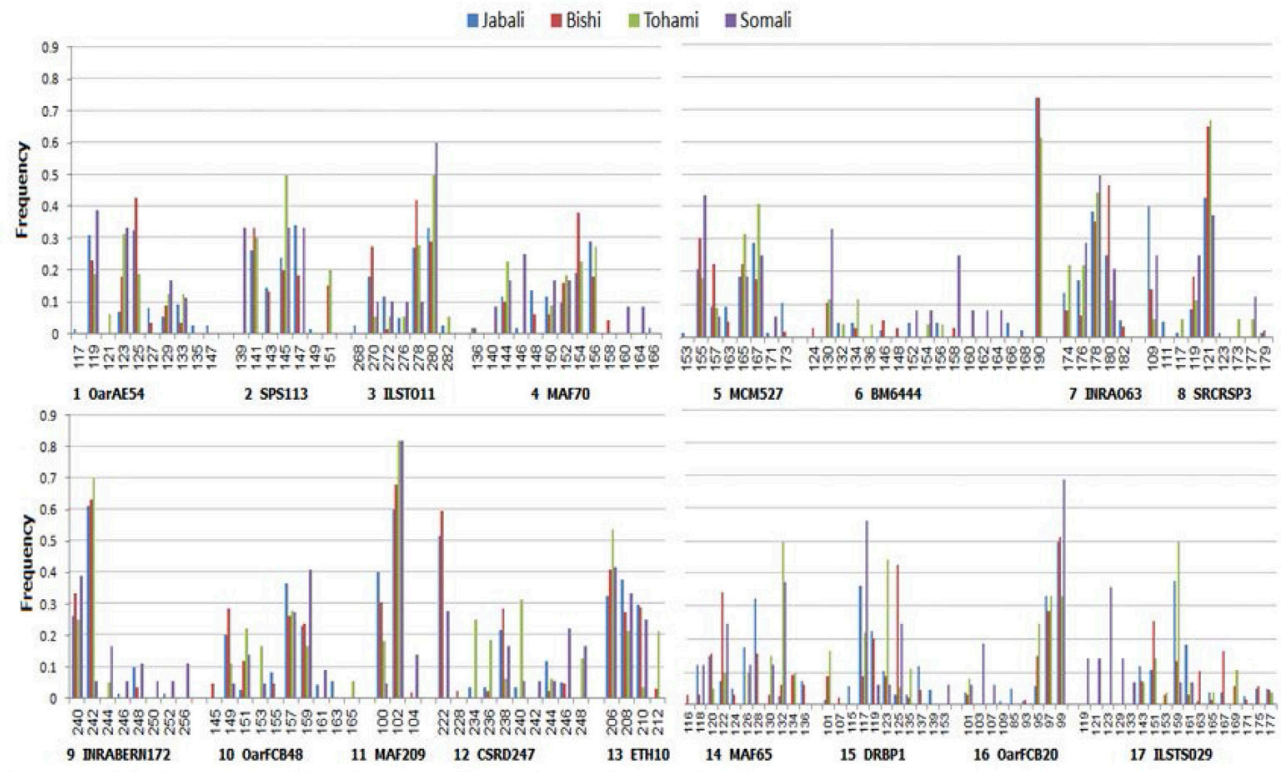

Figure 2. Allele frequency profiles of microsatellite markers in four goat breeds. 

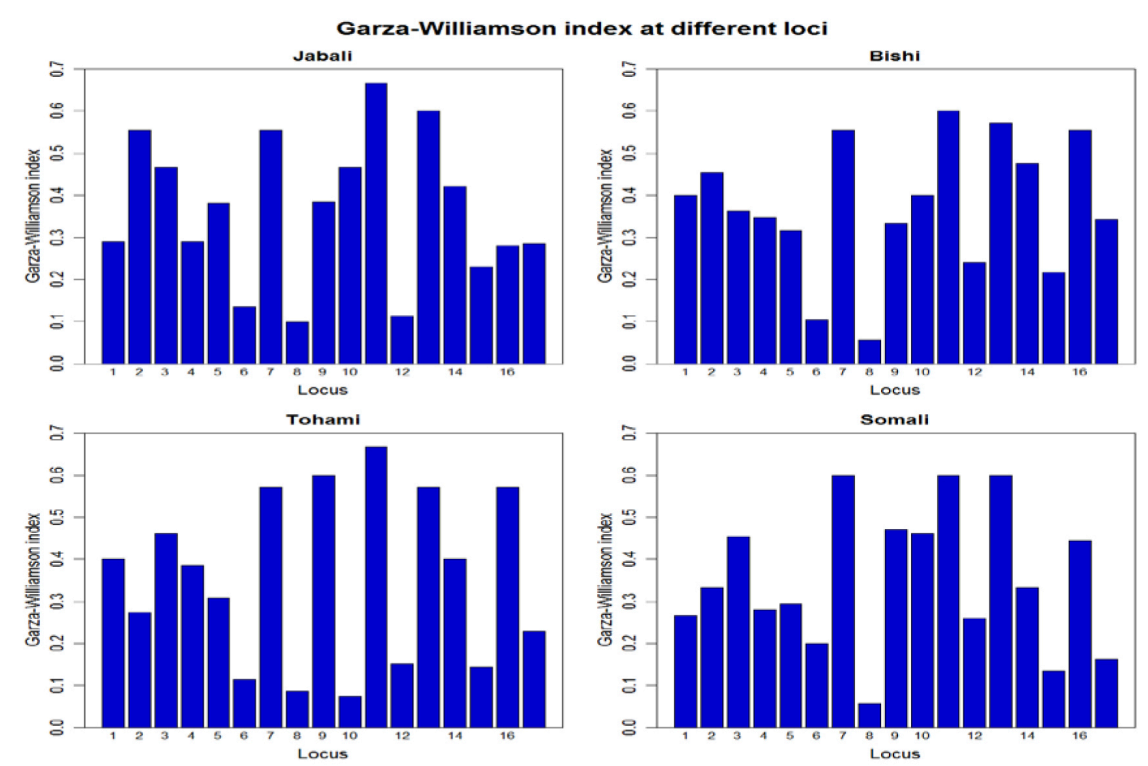

Figure 3. Garza-Williamson index at different loci in four goat breeds.

\section{Assignment of individuals to predefined breeds}

The results of determining the log-likelihood of each individual's multi-locus genotype in each breed, assuming the assigned individual came from that predefined breed, are presented in Figure 4. In general, the goats were assigned to the same breeds as those that were sampled based on their genotypes (Figure 4). However, there was one case where an individual thought to be a Bishi goat was assigned to the Jabali breed (Figure 4B). It is important to point out that the analysis provided a clear distinction between the Somali goats and the other goats (Figure 4D).

The results of the correspondence analysis are presented in Figure 5. The graphical representation of this analysis indicates three factorial dimensions that are based on the allele frequencies of the 17 markers. The first and second factors (axes 1 and 2) accounted for 48.85 and $31.43 \%$, respectively, of the total variation, and clearly distinguish Jabali, Bishi, and Tohami goats into three separate groups (Figure 5). Jabali goats appeared to be closely related to Bishi goats, with a few mixed-breed individuals. The Somali goats were distinguished from each other and from individuals of the other three breeds.

\section{DISCUSSION}

There were significant deviations from the Hardy-Weinberg equilibrium at loci MAF70 and ETH10 in Jabali goats, and at OarFCB20 in Bishi goats $(\mathrm{P}<0.05)$. There were a large number of marker alleles in the breeds, except for MAF209 and ETH10, at which only three and four alleles, respectively, were observed. Six loci (OarAE54, SPS113, MAF70, INRABERN172, MAF209, and DRBP1) had normal allele frequency distributions. Although the other allele frequency profiles had no specific pattern, some obvious similarities were 


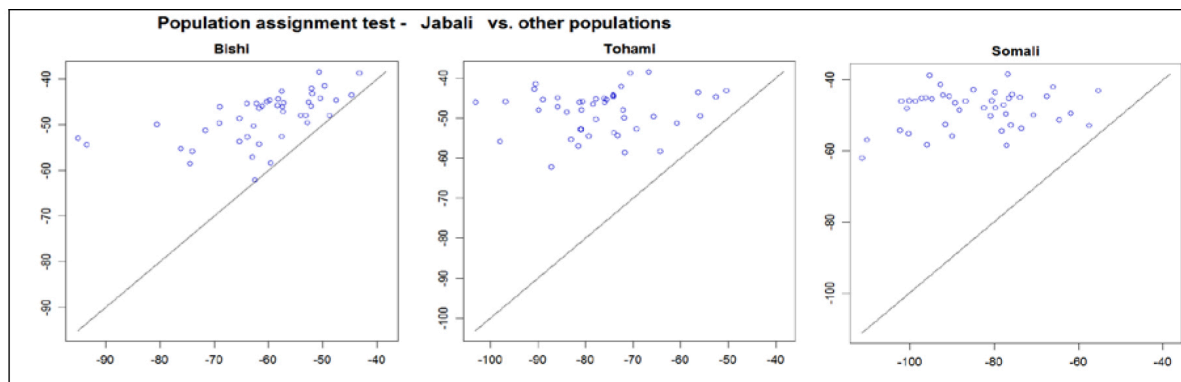

A
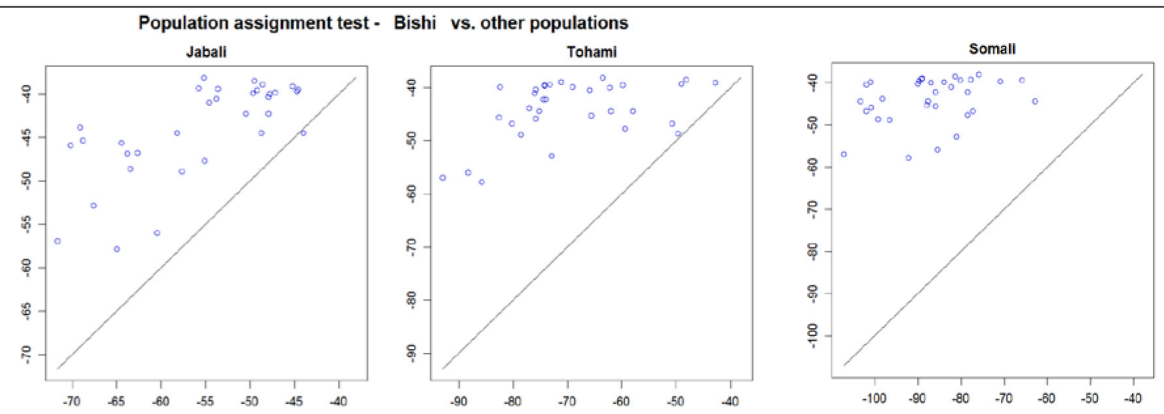

B.
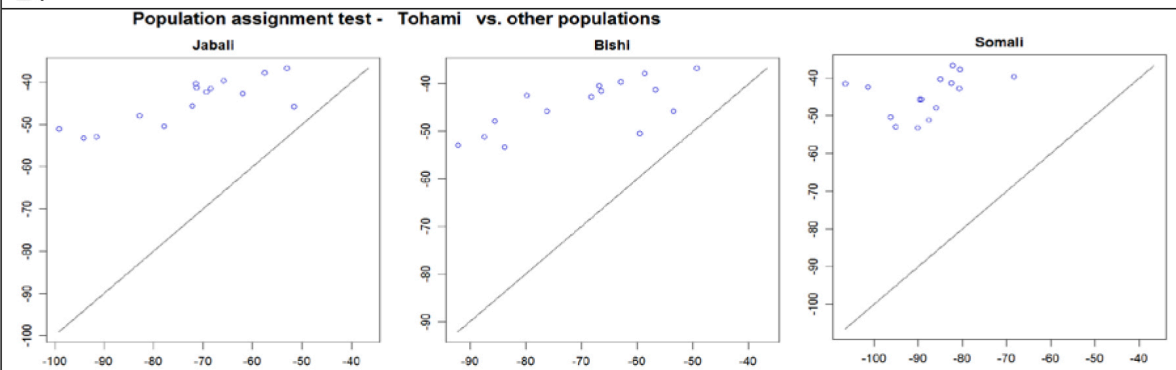

C.
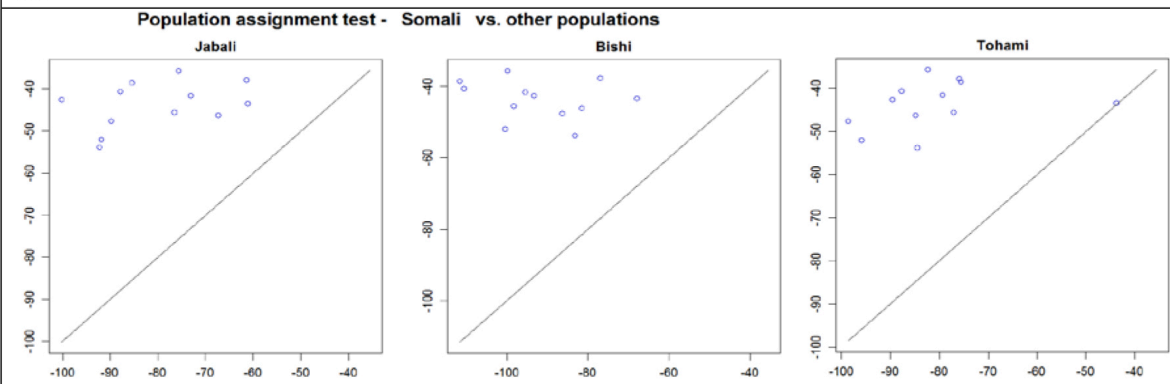

D.

Figure 4. Log-likelihood assignment of individual goats to four breeds. 


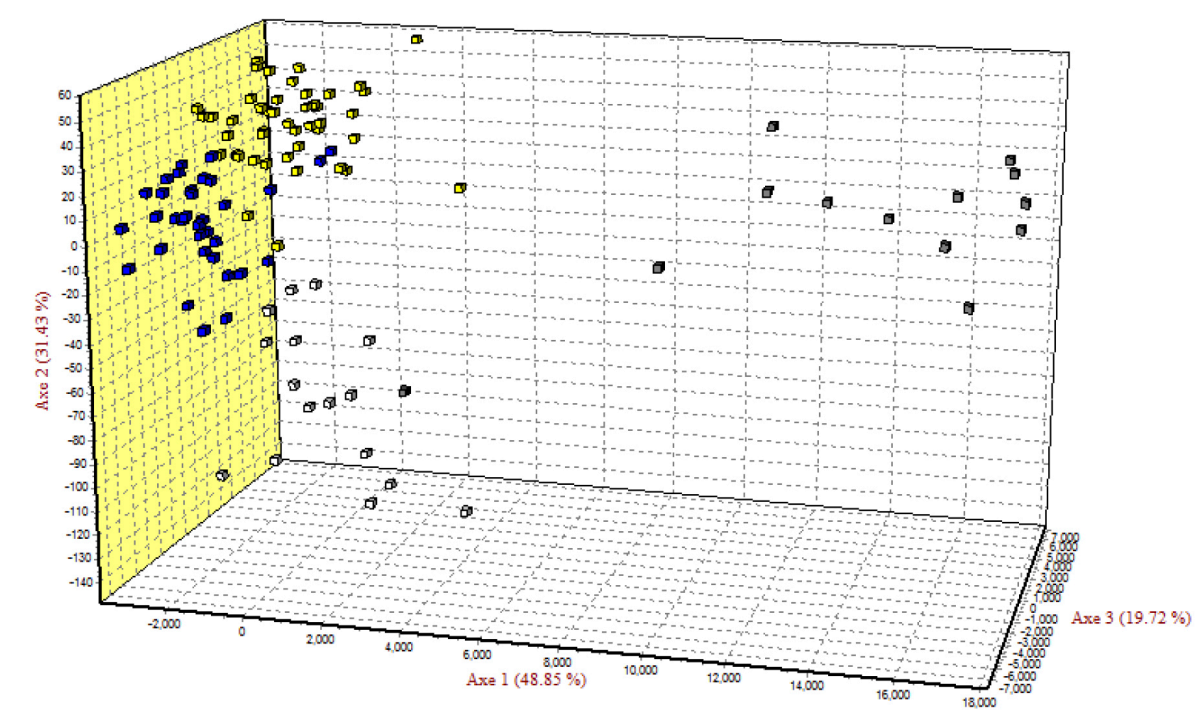

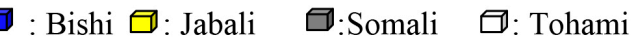

Figure 5. Correspondence analysis of individual genotypes of four goat breeds.

noticed, such as between BM6444, SRSRSP3, OArFCB48, MAF65, OarFCB20, and ILSTS029. Allele 102 at MAF209 was the most frequently found allele in the four breeds, followed by allele 190 at BM6444 in the three Saudi breeds. The most frequent allele in Tohami goats was allele 132 atMAF65. We found 51 private alleles, some at a high frequency. Similar results were recently reported in the Ardi Saudi goat showing a large number of alleles and high level of polymorphism (Aljumaah et al., 2012).

The largest number of private alleles was found in Somali goats (19), 17 were found in Jabali goats, 8 were found in Tohami goats, and 7 were found in Bishi goats. The frequencies of private alleles ranged from $10 \%$ for allele 242 at locus OarFCB 48 in the Tohami breed to $33 \%$ for allele 139 at locus SPS113 in Somali goats. These results indicate that there is a low level of gene flow between these two breeds.

The direct assignment test of the four breeds showed that individuals were assigned according to their predefined breeds, except for two cases where Jabali goats intermixed with Bishi goats and Tohami goats intermixed with Somali goats. An individual that was thought to be a Bishi goat was assigned to the Jabali breed. It is important to note that this result was based on the individual's genotype. Therefore, knowing the individuals' genotypes was enough to distinguish between Somali and Saudi goats. This result is in accordance with studies that have conducted genetic assignments within and between breeds, and reconstructed the histories of ancestral breeds (Hannotte and Jianlin, 2005; Groeneveld et al., 2010). The assignment analysis was earlier reported for Beeshi (Bishi) and Najrani (Jabali) individuals by 70 and $80.0 \%$, respectively (Canon et al., 2006). The three-factorial correspondence analysis clearly distinguished the Saudi breeds from each other and from the Somali breed. The same analysis was successfully used by Bolormaa et al. (2008). Jabali goats appeared to be closely related to Bishi goats, with a few mixed-breed individuals. The Somali goats were 
distinguished from each other and from individuals of the Saudi breeds. The analysis found that the Saudi breeds were subdivided in a cluster away from Somali goats. Management factors, such as the limited exchange of Somali goats to one of the other breeds, may occur. These results indicate that gene flow occurs between Jabali and Bishi goats. Similarly, Magdalena et al. (2009) reported that gene flow was the main reason why the Guadarrama goat breed was different from other Spanish breeds. In addition, Al-Atiyat and Aljumaah (2014) reported a high divergence between Saudi goats and goats from Jordan and Syria. They reported mixedbreed individuals caused by occasional migration from the two neighboring countries to Saudi Arabia. Our results confirm the results of previous studies that have found that microsatellite markers can assign goats to their breeds (Araújo et al., 2006; Bruno-de-Sousa et al., 2010). In conclusion, the results of a correspondence analysis based on 17 MS genotypes were clearly successful in distinguishing the KSA breeds from each other and from Somali goat breed.

\section{ACKNOWLEDGMENTS}

The authors would like to thank the Deanship of Scientific Research at King Saud University for funding (\#RG-1435-064).

\section{REFERENCES}

Al-Amer M (2003). Heat tolerance of local goat breeds in Saudi Arabia. Arab Gulf J. Sci. Res. 21: 210-216.

Al-Atiyat RM and Aljumaah RS (2014). Genetic relatedness between Ardi, Black Bedouin and Damascus goat breeds. Genet. Mol. Res. 13: 4654-4665.

Aljumaah R, Musthafa M, Al-Shaikh M, Badri O, et al. (2012). Genetic diversity of Ardi goat based on microsatellite analysis. Afr. J. Biotechnol. 11: 16539-16545.

Al-Khouri H (1996). The encyclopedia of goat breeds in the Arab countries and the conservation of biodiversity and environments in Arab countries. Arab Centre for Studies of Arid Zones and Dry Lands (ACSAD). Syrian Arab Republic.

Araújo A, Facioni SE, Guimaraes TMM, Machado PSL, et al. (2006). Genetic diversity between herds of Alpine and Saanen dairy goats and the naturalized Brazilian Moxoto breed. Genet. Mol. Biol. 29: 67-74.

Belkhir K, Borsa P, Chikhi L, Raufaste N, et al. (1996-2002). GENETIX 4.04, Logiciel sous Windows TM pour la genétique des populations. Laboratories Genome, Populations, Interactions, CNRS UMR 5000, Université de Montpellier II, Montpellier.

Bolormaa S, Ruvinsky A, Walkden-Brown S and van der Werf J (2008). Genetic relationships among Australian and Mongolian fleece-bearing goats. Asian-Aust. J. Anim. Sci. 21: 1535-1543.

Bruno-de-Sousa C, Martinez AM, Ginja C, Santos-Silva F, et al. (2010). Genetic diversity and population structure in Portuguese goat breeds. Livestock Sci. 135: 131-139.

Canon J, García D, García-Atance MA, Obexer-Ruff G, et al. (2006). Geographical partitioning of goat diversity in Europe and the Middle East. Anim. Genet. 37: 327-334.

Castric V and Bernatchez L (2004). Individual assignment test reveals differential restriction to dispersal between two salmonids despite no increase of genetic differences with distance. Mol. Ecol. 13: 1299-312.

Cegelski CC, Waits LP and Anderson NJ (2003) Assessing population structure and gene flow in Montana wolverines (Gulo gulo) using assignment-based approaches. Mol. Ecol. 12: 2907-2918.

Evett IW and Weir BS (1998). Interpreting DNA evidence: statistical genetics for forensic scientists. Sinauer Associates, Sunderland.

Excoffier L, Laval G and Schneider S (2005). Arlequin ver. 3.0: An integrated software package for population genetics data analysis. Evol. Bioinform. Online 1:47-50.

FAOSTAT (2013). FAO Statistical Yearbook 2013. Available at [http://faostat.fao.org/site/291/default.aspx].

FAO (Food and Agriculture Organization) (2004). Conservation strategies for animal genetic resources.FAO, Rome, Italy.

FAO (Food and Agriculture Organization) (2007). The state of the world's animal genetic resources for food and agriculture. Commission on Genetic Resources for Food and Agriculture of the United Nations, Rome, Italy. 
Galal S (2005). Biodiversity in goats. Small Rum. Res. 60: 75-81.

Garza JC and Williamson EG (2001). Detection of reduction in population size using data from microsatellite loci. Mol. Ecol. 10: 305-318.

Groeneveld LF, Lenstra JA, Eding H, Toro MA, et al. (2010). Genetic diversity in farm animals-a review. Anim. Genet. 41: 6-31.

Hannotte O and Jianlin H (2005). Genetic characterization of livestock populations and its use in conservation decision making. In: The role of biotechnology in exploring and protecting genetic resources (Ruane J and Sannino A, eds.). FAO, Rome, 89-96.

Magdalena S, Jorge HC, Marta M, Ane MC, et al. (2009). Microsatellite-based genetic diversity and population structure of the endangered Spanish Guadarrama goat breed. BMC Genet. 10: 61-65.

Marshall TC, Slate J, Kruuk LE, Pemberton JM (1998). Statistical confidence for likelihood-based paternity inference in natural populations. Mol. Ecol. 7: 639-655.

Paetkau D, Calvert W, Stirling I and Strobeck C (1995). Microsatellite analysis of population structure in Canadian polar bears. Mol. Ecol. 4: 347-354.

Peter C, Bruford M, Peretz T, Dalamitra S, et al. (2006). Genetic diversity and subdivision of 57 European and MiddleEastern sheep breeds. Anim. Genet. 38: 37-44.

Peters KJ and Horst P (1981). Development potential of goat breeding in the tropics and subtropics. Anim. Res. Dev. 14: 54-71.

Pritchard JK, Stephens M and Donnelly P (2000). Inference of population structure using multilocus genotype data. Genetics 155: 945-959.

Rodero EA, Camachoa ME, Delgadoa VJ and Roderoa A (1992). Study of the Andalusian minor breeds: evaluation of the priorities of conservation. Genetics 10: 35-42.

Sambrook J, Fritsch EF and Maniatis T (1989). Molecular cloning: A laboratory manual. Cold Spring Harbor Laboratory Press, New York.

Selkoe KA and Toonen RJ (2006). Microsatellites for ecologists: a practical guide to using and evaluating microsatellite markers. Ecol. Lett. 9: 615-629.

Shackell GH, Tate ML and Anderson RM (2001). Installing a DNA-based traceability system in the meat industry. Proc. Assoc. Advmt. Anim. Breed. Genet. 14: 533-536.

Sunnucks P (2001). Efficient genetic markers for population biology. Trends Ecol. Evol. 15: 199-203. 